\title{
Pemanfaatan Media Sosial Sebagai Sarana Sosialisasi Kegiatan Masjid Di Yayasan As Salam Joglo
}

\author{
Mulia Rahmayu ${ }^{1}$, Dikdik Permana Wigandi' ${ }^{2}$, Asri Wahyuni ${ }^{3}$, Agus Yulianto $^{4}$, Iwan $^{5}$ \\ 1,2,3,4,5 Universitas Nusa Mandiri \\ Jl. Jatiwaringin Raya N0. 02 RT 08 RW 013 Kelurahan Cipinang Melayu Kecamatan \\ Makasar Jakarta Timur Kode Pos 13620 \\ e-mail: ${ }^{1}$ mulia.mlh@ nusamandiri.ac.id, ${ }^{2}$ dikdik.dkn@ nusamandiri.ac.id, \\ ${ }^{3}$ asri.awx@nusamandiri.ac.id, ${ }^{4}$ agus.aag@nusamandiri.ac.id, ${ }^{5}$ iwan.iwx@nusamandiri.ac.id
}

\begin{abstract}
Abstrak
Masjid selain menjadi tempat ibadah juga sekaligus dapat menjadi tempat untuk menambah wawasan, dengan mengikuti kegiatan masjid seperti kajian Islam. Masjid As Salam yang terletak di Joglo juga mempunyai banyak kegiatan yang diadakan seperti kajian ceramah rutin, buka bersama, mabit, dan lain sebagainya. Semenjak pandemi, beberapa kegiatan masjid secara offline diberhentikan dahulu krn banyaknya kasus yang positif di kalangan masyarakat. Tetapi beberapa kajian rutin tetap diadakan secara online. Agar masyarakat sekitar mengetahui, kiranya diperlukan media untuk sosialisasi seperti video. Video ceramah dapat diupload pada channel YouTube agar masyarakat dapat mengetahui kegiatan yang diadakan oleh Masjid As Salam. Namun keterampilan yang dimiliki oleh pengurus masjid masih begitu minim dalam hal editing video dan membuat konten yang menarik. Oleh sebab itu, tujuan diadakan pelatihan dari kegiatan ini yaitu memberikan pengembangan kepada pengurus Masjid Yayasan As Salam dalam membuat konten yang menarik sebagai media sosialisasi kegiatan Masjid As-Salam. Metode pelaksanaan yang digunakan dalam menyelesaikan permasalahan pada pengurus Mesjid di Yaysan As-Salam Joglo dilakukan secara offline (oleh beberapa panitia dengan protokol kesehatan yang ketat.) dan online (bagi panitia yang tidak bisa datang ke lokasi, karena pembatasan kerumunan orang). Target Peserta Pengabdian Masyarakat ini adalah 20 orang peserta. Hasil dari kegiatan ini yaitu Keterampilan pengurus dalam bidang pembuatan dan editing cover video konten meningkat $80 \%$, Keterampilan pengurus dalam bidang pembuatan dan editing video konten meningkat $70 \%$ dan Keterampilan pengurus dalam bidang publikasi, promosi, dan sosialisasi meningkat $90 \%$.
\end{abstract}

Kata Kunci: Video, Ceramah, Media Sosial

\section{Abstract}

The mosque is not only a place of worship but also a place to add insight, by participating in mosque activities such as Islamic studies. As Salam Mosque which is located in Joglo also has many activities held such as regular lecture studies, breaking fast, mabit, and so on. Since the pandemic, several offline mosque activities have been suspended due to the large number of positive cases in the community. But some regular studies are still being conducted online. In order for the surrounding community to know, media for socialization, such as video, would be needed. Video lectures can be uploaded on the YouTube channel so that the public can find out about the activities held by Masjid As Salam. However, the skills possessed by 
mosque administrators are still minimal in terms of video editing and creating interesting content. Therefore, the purpose of the training from this activity is to provide development to the management of the Masjid As Salam Foundation in creating interesting content as a medium for socializing the activities of the As-Salam Mosque. The implementation method used in solving problems for the mosque management at Yaysan As-Salam Joglo is done offline (by several committees with strict health protocols.) and online (for committees who cannot come to the location, due to crowd restrictions). The target audience for this Community Service is 20 participants. The results of this activity are the skills of the management in the field of making and editing video content covers increased by $80 \%$, the skills of the administrators in the field of video content creation and editing increased by $70 \%$ and the skills of the administrators in the fields of publication, promotion, and socialization increased by $90 \%$.

Keywords: Video, Lecture, Social Media

\section{Pendahuluan}

Perkembangan teknologi informasi di era modern ini semakin pesat di dalam kehidupan masyarakat. Internet adalah salah satu media dari teknologi informasi tersebut yang memiliki perkembangan tercepat dari teknologi-teknologi lainnya. Dalam buku Teknologi Informasi dan Komunikasi karangan Hendri Pondia disebutkan bahwa internet adalah sekumpulan komputer yang terhubung satu dengan yang lain dalam sebuah jaringan. Disebut jaringan yang saling terhubung karena internet menghubungkan komputer-komputer dan jaringan komputer yang ada di seluruh dunia menjadi sebuah jaringan komputer yang sangat besar. Perkembangan tersebut memberikan dampak positif dan negatif yang dapat mempengaruhi kehidupan manusia termasuk di dalamnya kehidupan beragama. Pandemi COVID-19 yang tengah melanda dunia menyebabkan semakin banyaknya masyarakat yang menggunakan internet, khususnya media sosial sebagai alternatif komunikasi dan pekerjaan lainnya.(Khosyatillah, 2018)

Guna menanggapi atau melawan fenomena tersebut disinilah dakwah berperan dalam perkembangan IPTEK yang semakin canggih terutama media sosial, karena dakwah sebagai tameng untuk melawan hal-hal negatif bagi umat Islam. Dakwah berasal dari kata da yad"e $u$ - da ${ }^{\text {ee }}$ watan yang artinya mengajak atau menyeru, sedangakan secara harfiah dakwah berarti mengajak atau menyeru kepada sesama umat Islam kepada hal-hal dan tindakan amar ma"eruf nahi munkar. Dakwah yang dilakukan dengan ceramah saat ini sudah sangat populer di berbagai kalangan dan banyak dilakukan oleh para da ${ }^{e i}$ sehingga tidak memungkiri jika berdakwah dengan metode ceramah diatas mimbar terkesan monoton dan membuat mad"e $u$ merasa jenuh jika dilakukan secara terus-menerus di era milenial seperti sekarang. Maka selain ceramah, da ${ }^{e e} i$ memerlukan media dakwah yang lebih inovatif dan kreatif sehingga tidak membuat jenuh dan tidak kehilangan simpati dari mad"u. Kecanggihan teknologi informasi dan komunikasi yang semakin berkembang ini membuat dakwah menjadi lebih mudah untuk disampaikan. Banyak media yang dapat kita manfaatkan untuk mensyiarkan dakwah, seperti yang sering kita jumpai sekarang ini banyak akun-akun dakwah yang bertebaran di media sosial seperti Instagram, Facebook, Youtube dan lainnya.(YoanAzkiya, 2020) 
Dakwah virtual telah menjadi alternatif dalam dakwah di era digital. Pemanfaatan media sosial untuk berdakwah secara virtual ini kemudian dapat menjadi saluran (channel) dakwah yang efektif jika dirancang dengan kreatif melalui pesan-pesan yang menarik untuk dijadikan preferensi bagi remaja. Remaja masjid dapat melakukan aktivitas ibadah dan sosial melalui media sosial. Remaja masjid di wilayah perkotaan tentu memiliki tantangan tersendiri di tengah arus informasi dan hiburan yang mampu memapar kehidupan social remaja perkotaan.(Hariyati \& Wahdiyati, 2019).

Masjid As-Salam yang terletak di Jl. Masjid Assalam, RT.2/RW.4, Joglo, Kec. Kembangan, Kota Jakarta Barat, Daerah Khusus Ibukota Jakarta 11620 menjadi salah satu masjid yang diresmikan oleh Gubernur Jakarta Anies Baswedan pada bulan Mei 2018. Kegiatan masjid As-Salam yang diadakan oleh pengurus atau DKM masjid adalah kajian rutin yang tidak hanya diikuti oleh ikhwan tetapi oleh akhwat juga. Selain kegiatan-kegiatan tersebut, fungsi masjid juga menjadi tujuan utama yaitu tempat ibadah bagi orang muslim. Orang-orang muslim dapat beribadah dengan sholat berjamaah di masjid As-Salam,

Akibat pandemic ini hampir seluruh kegiatan masjid As-Salam tidak bisa dilakukan secara rutin lagi. Disinilah diperlukan ide kreatif dari para pengurus masjid agar kegiatan-kegiatan masjid dapat terus berjalan. Kegiatan yang bisa disalurkan lewat internet misalkan dakwah atau kegiatan sosialisasi lainnya.

Ada atau tiadanya keterlibatan media dalam sebuah transformasi sosial tetap memiliki makna sebagai sebuah proses dan tahapan perubahan bentuk dan hasilnya disebut dengan istilah transformatif. Secara perlahan proses transformasi akan membuahkan perubahan paradigma dalam beberapa hal, salah satunya paradigm kemasjidan. Ibadah yang awalnya hanya soal ritual seremonial berubah paradigmanya menjadi ibadah perspektif sosial. Aktivitas pemberdayaan masjid sejatinya perlu disertai instrumen lain seperti manajemen masjid yang baik, karena ketika manajemen disandarkan dengan kata masjid maka muncul pengharapan bahwa masjid tersebut akan menjadi masjid ideal (Islamy: 2003). Menurut Gazalba, masjid ideal yang dimaksud adalah masjid yang berfungsi selain sebagai pusat ibadah juga sebagai pusat peradaban (1996).(Muttaqin et al., 2020).

Untuk memberikan solusi atas permasalahan tersebut, akan diadakan program pelatihan pembuatan video yang bertujuan untuk meningkatkan keterampilan para pemuda/remaja/takmir dalam membuat video pendek kreatif untuk keperluan dakwah yang berisi sosialisasi kegiatan-kegiatan masjid.(Riyadi \& Sudiwijaya, 2020) Video yang dibuat akan diupload melalui channel YouTube. Melalui channel youtube ini, setiap orang dapat menyaksikan mubaligh yang menyampaikan ajaran-ajaran islam dengan media audio visual. Bukan hanya sekedar menulis dan berbicara di atas mimbar, kegiatan tabligh yang di laksanakan oleh pengurus DKM Masjid juga melalui on camera atau di depan kamera yang langsung di upload atau diunggah di channel youtube.(Mariyam et al., 2020) 


\section{ABDITEKNIKA}

Jurnal Pengabdian Kepada Masyarakat

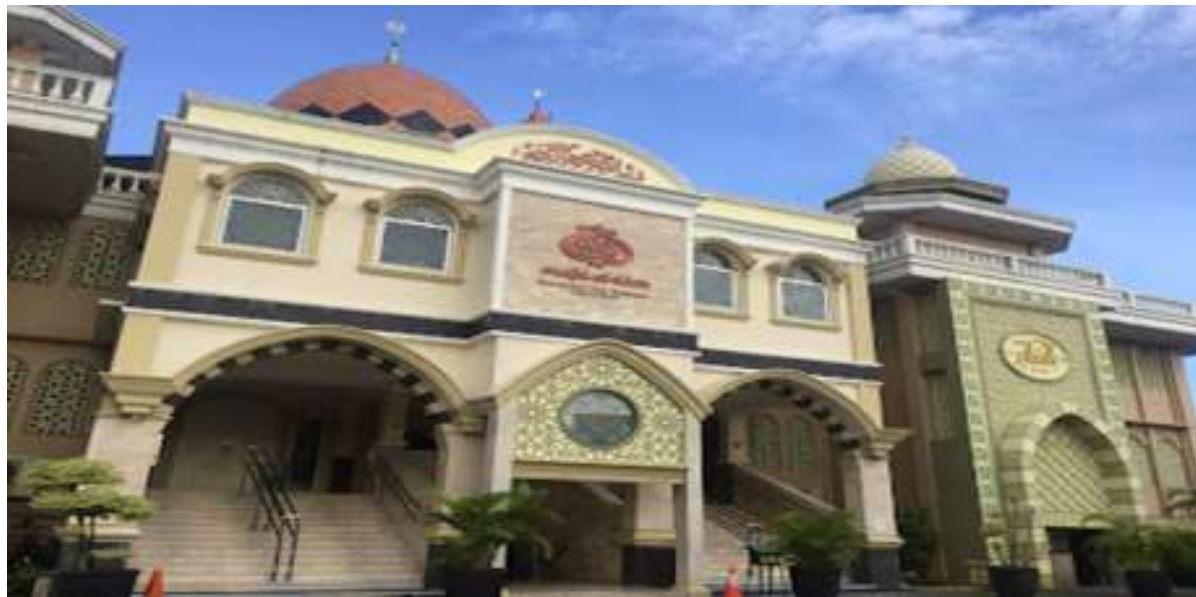

Gambar 1. Foto Mesjid As-Salam Joglo

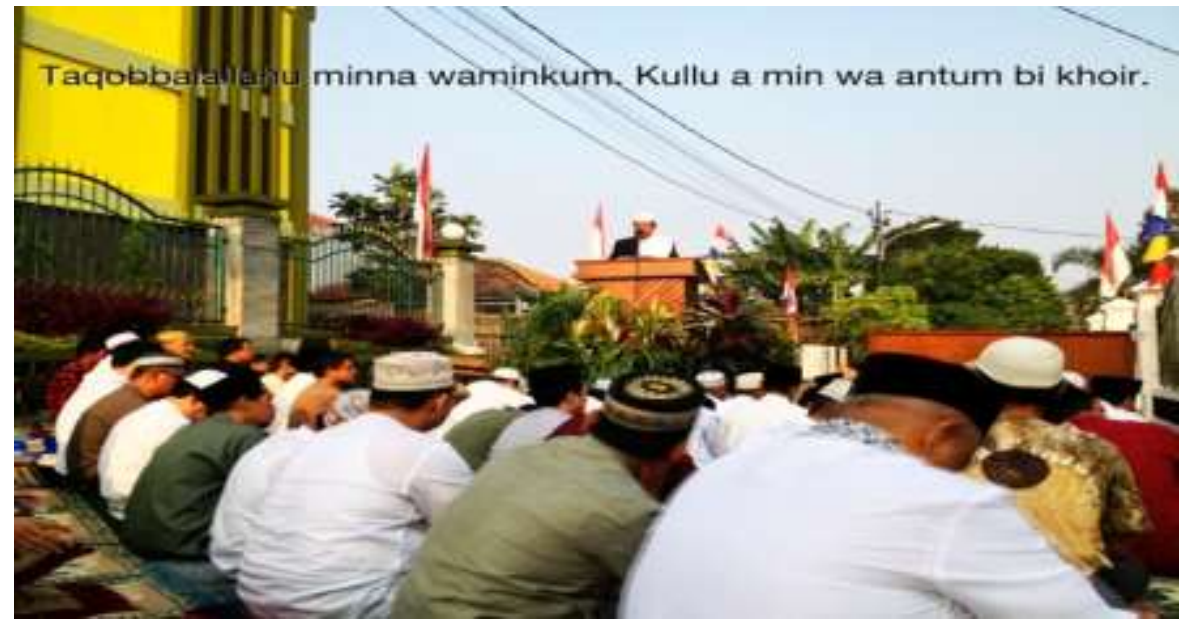

Gambar 2. Foto Kegiatan Dakwah di Mesjid As-Salam

https://id.foursquare.com/v/mesjid-as-salam-joglo/4c216d3513c00f47e50786de

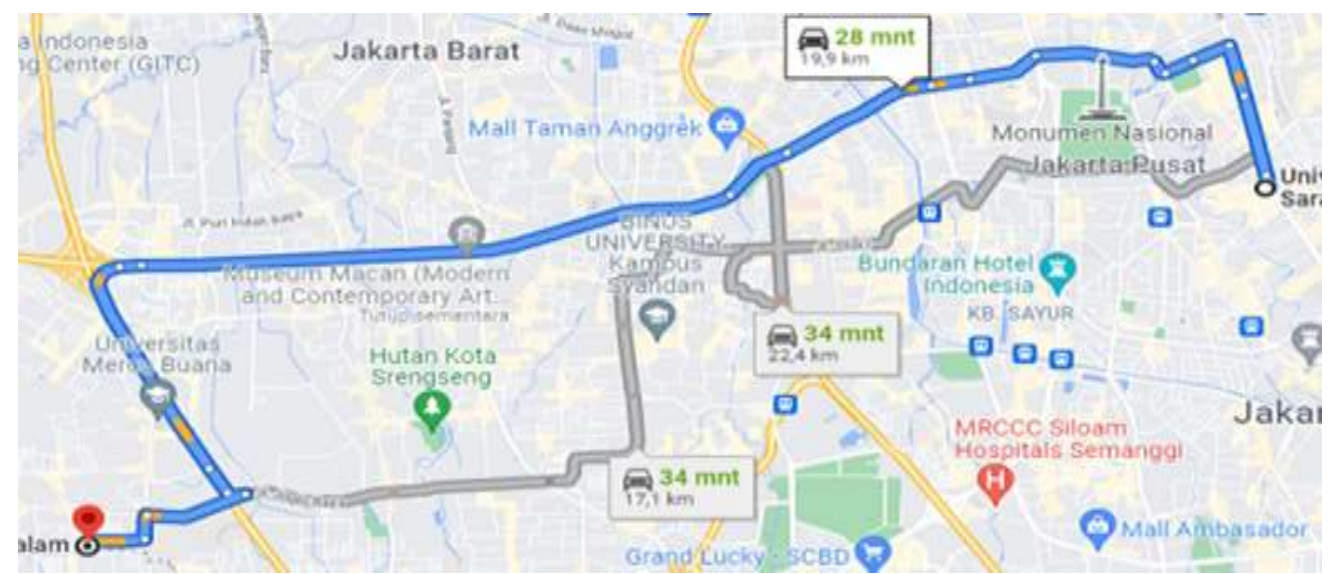

Gambar 3. Foto Peta Lokasi Mesjid As-Salam Joglo https://goo.gl/maps/X2TqRheAWMGfiSyL6

Jarak lokasi antara Universitas Nusa Mandiri yang berada di Kramat 18 dengan Masjid AsSalam Joglo yang terletak di alamat Jl. Masjid Assalam, RT.2/RW.4, Joglo, Kec. Kembangan, 
Kota Jakarta Barat, Daerah Khusus Ibukota Jakarta 11620 adalah 19,9 km dengan jarak tempuh kurang lebih 28 menit.

\section{Metode}

Metode pelaksanaan yang digunakan dalam menyelesaikan permasalahan pada Remaja Mesjid As-Salam Joglo dilakukan secara offline (oleh beberapa panitia dengan protokol kesehatan yang ketat.) dan online (bagi panitia dan mahasiswa yang tidak bisa datang ke lokasi, karena pembatasan kerumunan orang). Target Peserta Pengabdian Masyarakat ini adalah 20 orang peserta.

Berikut metode pelaksanaan yang digunakan pada pengabdian masyarakat di Mesjid AsSalam Joglo ini terdiri dari :

\section{A. Persiapan}

Tahap ini dilakukan untuk mengetahui permasalahan yang dihadapi oleh Pengurus Yayasan Mesjid As-Salam Joglo. Selanjutnya melakukan persiapan untuk pelatihan dengan membuat materi pelatihan membuat video melalui media sosial, serta membuat kuesioner sebagai bahan evaluasi.

Persiapan dilakukan dengan meminta izin dan memaparkan jenis kegiatan PM kepada Pengurus Yayasan Mesjid As-Salam Joglo. Setelah mendapatkan izin, kegiatan yang selanjutnya dilakukan adalah :

1. Observasi dan Wawancara

Pada tahap ini dilakukan observasi dengan mengamati beberapa kegiatan pada Masjid As-Salam Joglo. Sedangkan wawancara dilakukan terhadap Pengurus Yayasan Mesjid As-Salam Joglo. Wawancara dengan bertanya tentang kendala-kendala atau permasalahan yang dihadapi oleh Pengurus Yayasan Mesjid As-Salam Joglo dalam mensosialisasikan kegiatan-kegiatan masjid yang berhubungan dengan teknologi dan informasi.

2. Pencarian referensi

Pencarian referensi dilakukan pada media berbasis digital, dengan mencari beberapa contoh video yang tepat sesuai dengan permasalahan yang dihadapi yaitu kurangnya keahlian dalam pengembangan konten video di mesia sosial.

3. Pembuatan materi dan persiapan kuesioner

Tutor membuat persiapan yaitu pembuatan materi mengenai editing video yang bertujuan untuk mengembangkan konten kreatif dalam rangka sosialisasi kegiatan masjid. Kuesioner juga dipersiapkan untuk disebarkan kepada peserta PM untuk mengetahui bagaimana respon peserta terhadap pelatihan tersebut.

4. Persiapan Lain-Lain

Persiapan lain-lain terdiri dari alat dan perlengkapan PM seperti, spanduk, LCD projector, MIC (pengeras suara), persiapan untuk mendukung 3M yaitu hand sanitizer dan masker, juga persiapan tempat.

B. Pelaksanaan

Pelaksanaan diuraikan dalam 5 tahap yaitu :

1. Pemberian Materi

Materi akan diisi secara online oleh seorang tutor yang menjelaskan tentang bagaimana mengoptimalkan informasi melalui media digital agar dapat bisa mensosialisasikan kegiatan masjid.

2. Pelatihan Editing Video

Setelah selesai tahap pertama dan agar peserta tidak bosan dan dapat fresh kembali maka dilakukan ishoma. Setelah ishoma selesai, dilanjutkan dengan pelatihan editing video 
dengan salah satu software editing video seperti Kinemaster. Pada tahap ini akan dilaksanakan secara online karena tutor berhalangan hadir secara langsung. Tutor untuk pelatihan ini diambil dari dosen yang sudah berpengalaman di bidang Vlog. Selain pelatihan editing video, maka akan diajarkan juga bagaimana cara agar channel YouTube mempunyai banyak subscriber, banyak penonton, juga banyak jam tayang yang ditonton dari awal sampai selesai. Serta diajarkan juga agar cepat dan cara monetisasi.

3. Pengisian Kuesioner

Pengisian kuesioner dilakukan langsung di lokasi secara offline.

4. Dokumentasi

Dokumentasi dilakukan di sela-sela kegiatan dan di sesi akhir dari acara ini adalah dokumentasi seluruh peserta yaitu pengurus masjid beserta panitia.

\section{Hasil dan Pembahasan}

Hasil yang dicapai dalam kegiatan ini yaitu memberi wawasan terbaru dalam hal mengedit video konten di sosial media untuk pengurus Masjid di Yaysan As-Salam Joglo. Sehingga mereka dapat mempraktekan di kehidupan sehari-sehari untuk dapat mengelola kegiatankegiatan Mesjid yang dapat diinformasikan melalui internet saat pandemik ini. Selama mengikuti kegiatan ini para pengurus Masjid As-Salam Joglo sangat antusias dalam memahami materi yang disampaikan.

Hasil dari kegiatan ini selain memberikan penyuluhan/pelatihan cara membuat konten video di media sosial, kegiatan ini juga mengupas sebuah konten di Youtube yang mengupload video Sosialisasi Ambulance Masjid As Salam Joglo dengan pemilik akun BARAKNA. Kami memberikan masukan-masukan berupa saran untuk konten video tersebut agar nantinya pengurus Masjid As Salam dapat membuat konten video di Youtube lebih menarik lagi.

Berikut contoh tampilan konten video Youtube yang telah dibuat oleh pengurus Masjid As Salam Joglo :

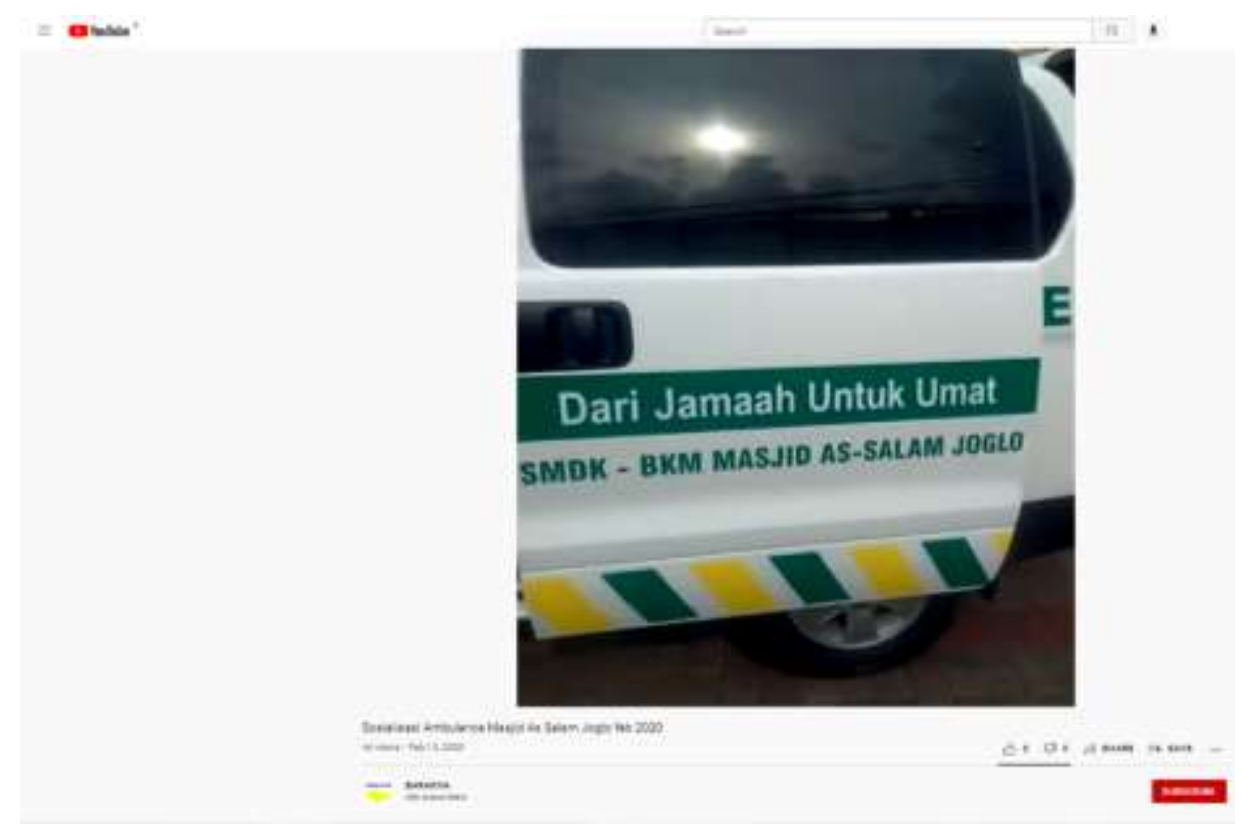

Gambar 4. Tampilan Konten Video Buatan Pengurus Masjid As Salam Joglo 
Pelaksanaan Pengabdian Masyarakat ini dilaksanakan di lingkungan Mesjid As-Salam Joglo dalam bentuk workshop pelatihan membuat konten video di media sosial dengan menggunakan Zoom Meeting dan target peserta dari kegiatan ini yaitu remaja pengurus Mesjid As-Salam Joglo berjumlah 20 orang dengan Zoom Meeting https://us02web.zoom.us/j/2036018574?pwd=R0wyNTkvTmJpdkpNczRoMGM4QmxXZz09 Meeting ID: 2036018574 Passcode: MIHBR.

Berikut hasil kegiatan dari permasalahan Mitra yang dapat dilakukan setelah pelaksanaan kegiatan pengabdian masyarakat yang sudah dituangkan dalam bentuk tabel 1 .

Tabel 1. Hasil Kegiatan dari Permasalahan Mitra

\begin{tabular}{l}
\hline Permasalahan \\
\hline Minimnya keterampilan \\
dalam pembuatan cover video \\
dan editing foto agar video \\
terlihat lebih menarik dalam \\
segi warna, posisi dan \\
penambahan caption.
\end{tabular}

Minimnya keterampilan pengurus dalam membuat konten dan pengeditan video agar lebih menarik dengan penambahan background lagu, suara, dan caption yang dapat juga dijadikan tolak ukur peningkatan kemampuan.

Publikasi dan promosi hanya melalui mulut ke mulut, sehingga kurang luasnya pemasaran. Hanya orangorang sekitar yang dekat dengan masjid saja yang mengetahui tentang kegiatan masjid As-Salam Joglo.

\section{Solusi}

Pelatihan pembuatan cover video konten dan editing foto dengan software gratis dan berbayar akan membuat video menjadi lebih menarik untuk ditonton dan akan memudahkan pengurus dalam mempromosikan, mempublikasikan, juga mensosialisasi kegiatan masjid kepada masyarakat luas masyarakat luas.

Pelatihan pembuatan konten dan editing video dengan software editing video gratis dan berbayar yang dapat membuat video menjadi lebih inovatif dan menarik, sehingga memudahkan pengurus dalam mengembangkan dakwah melalui kegiatan masjid yang dipublikasikan secara online walaupun adanya pandemi

Pelatihan publikasi dan pemasaran online sebagai digital marketing untuk mempromosikan kegiatankegiatan yang dilaksanakan di area masjid. Pemasaran akan dilakukan pada YouTube. Hal ini akan memudahkan pengurus dalam meningkatkan jumlah jama'ah.

\section{Hasil Setelah Kegiatan}

Keterampilan pengurus dalam bidang pembuatan dan editing cover video konten meningkat $80 \%$

Keterampilan pengurus dalam bidang pembuatan dan editing video konten meningkat $70 \%$

Keterampilan pengurus dalam bidang publikasi, promosi, dan sosialisasi meningkat $90 \%$ 


\section{ABDITEKNIKA}

Jurnal Pengabdian Kepada Masyarakat

Volume 1 Nomor 2 Oktober 2021

ISSN 2775-1694

Berikut beberapa foto dari pelaksanan kegiatan Pengabdian Masyarakat di Masjid As-Salam Joglo :

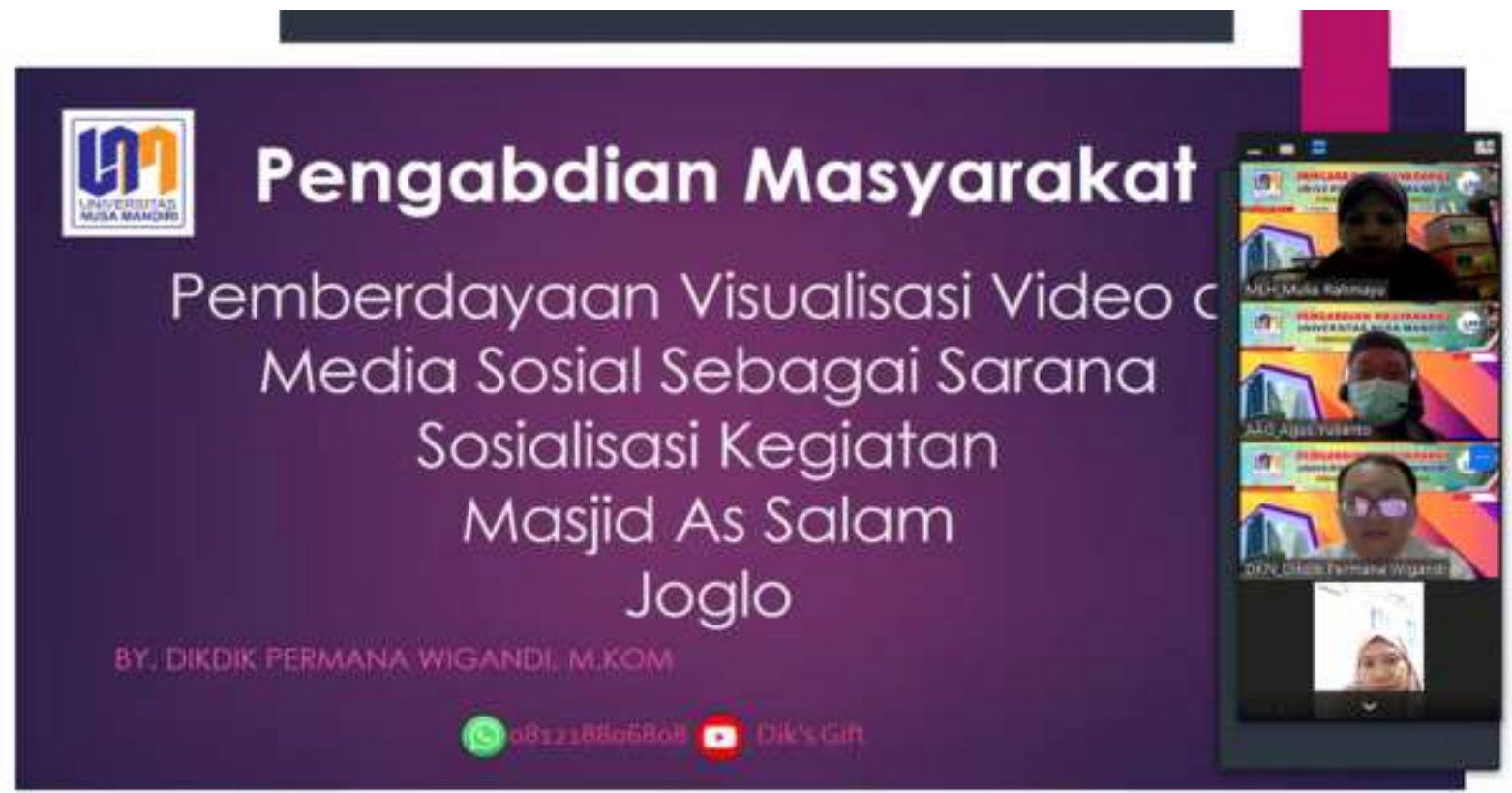

Gambar 5. Pemaparan materi oleh tutor

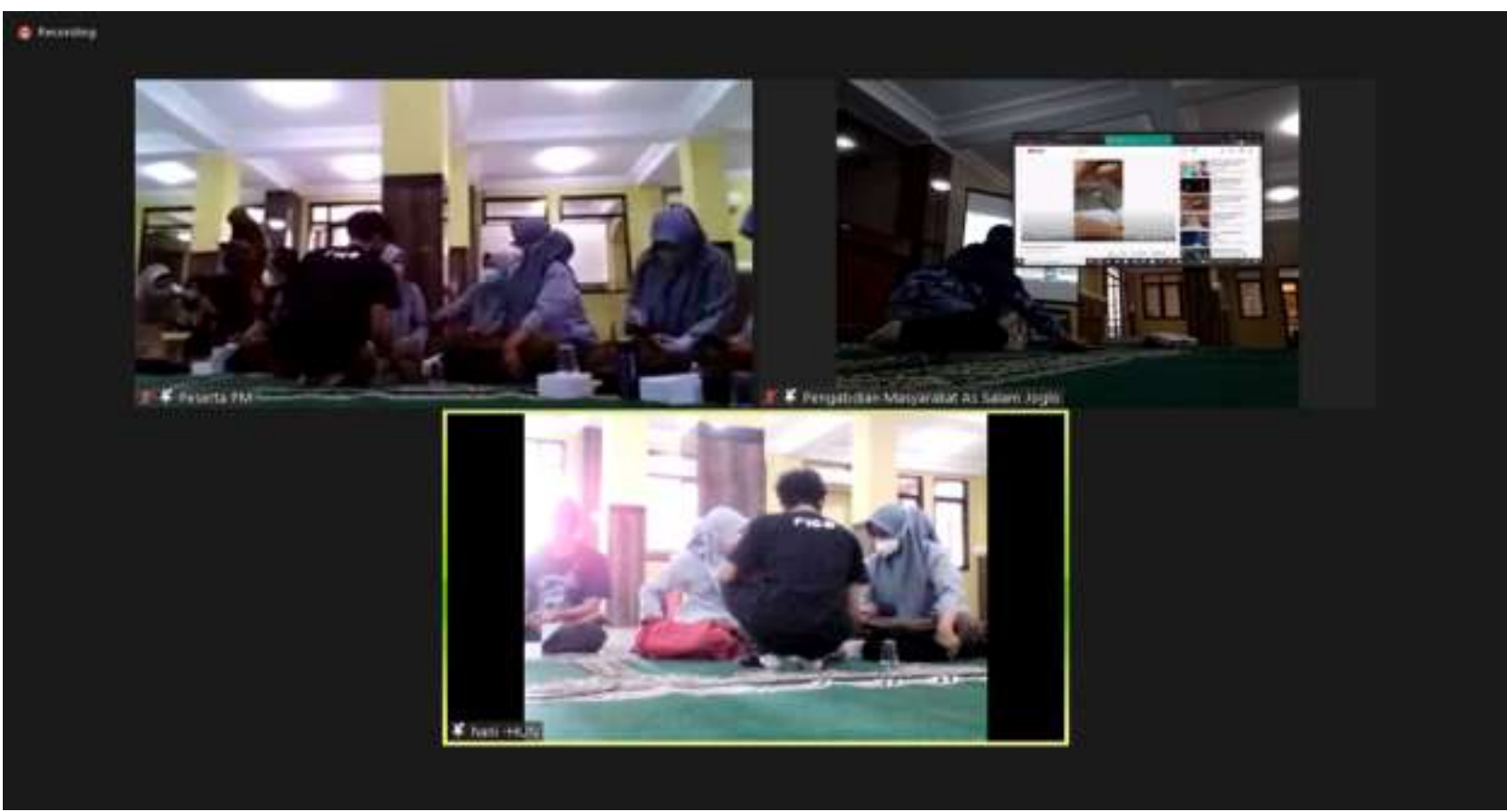

Gambar 6. Peserta PM antusias mendengarkan materi

\section{Kesimpulan}

Para peserta dan mitra sangat terbantu dengan adanya kegiatan ini karena telah memberikan penyuluhan/pelatihan cara membuat konten video di media sosial untuk membantu mengelola kegiatan-kegiatan di Masjid yang dapat diinformasikan melalui internet di masa pandemi ini. Selain itu kegiatan pengabdian masyarakat ini juga meningkatkan kemampuan, pengetahuan 
dan wawasan bagi para remaja pengurus Masjid As-Salam Joglo untuk mengedit video di media sosial di masa pandemi. Hasil dari kegiatan ini yaitu :

1. Keterampilan pengurus dalam bidang pembuatan dan editing cover video konten meningkat $80 \%$

2. Keterampilan pengurus dalam bidang pembuatan dan editing video konten meningkat $70 \%$

3. Keterampilan pengurus dalam bidang publikasi, promosi, dan sosialisasi meningkat 90 $\%$

\section{Daftar Pustaka}

Hariyati, F., \& Wahdiyati, D. (2019). Penguatan Dakwah Virtual Sebagai Upaya Memakmurkan Masjid Berbasis Kegiatan Remaja Masjid. Jurnal solma, 8(2), 239. https://doi.org/10.29405/solma.v8i2.3392

Khosyatillah, A. (2018). Dampak Media Sosial Terhadap Perilaku Keagamaan (Studi Kasus 7 Mahasiswa Jurusan Studi Agama Fakultas Ushuluddin dan Filsafat Universitas Islam Negeri Sunan Ampel Surabaya).

Mariyam, S., Abidin, Y. Z., \& Rosyidi, I. (2020). Manajemen Komunikasi Publikasi Kegiatan Masjid Agung Trans Studio Bandung. Prophetica : Scientific and Research Journal of Islamic Communication and Broadcasting, 6(1), 33-50.

https://doi.org/10.15575/prophetica.v6i1.2225

Muttaqin, H., Wahidin, K., Maulana, M. A., \& Juarsih, J. (2020). Pemberdayaan Jamaah Masjid Dan Penanggulangan Dampak Pandemi Covid-19. An-Nufus, 2(1), 58-76. https://e-journal.umc.ac.id/index.php/ANN/article/view/1651

Riyadi, S., \& Sudiwijaya, E. (2020). Peningkatan Ketrampilan Pengembangan Multimedia Kreatif Untuk Dakwah. 2219-2228. https://doi.org/10.18196/ppm.311.263

YoanAzkiya, M. (2020). Konsep Pengembangan Dan Pengelolaan Media Dakwah Visual Di Instagram Pondok Pesantren Darussalam Skripsi.

http://repository.iainpurwokerto.ac.id/7438/ 